\title{
Solvent-less Repair Inks for Color Filters
}

\author{
Huang-Ming Philip Chen ${ }^{1}$ Feng-Chin Tang ${ }^{1,2}$, Chi-Hsin $\mathrm{Li}^{2}$, Wen-Jen Hsieh ${ }^{2}$, and Yu-Chuan $\mathrm{Lin}^{2}$ \\ ${ }^{1}$ Department of Photonics and Display Institute, National Chiao Tung University, Hsinchu, Taiwan, \\ 30010 R.O.C. \\ ${ }^{2}$ Chunghwa Picture Tubes, Ltd., Taiwan
}

\begin{abstract}
Color filter (CF), one of the key components for liquid crystal display (LCD), is costly to make from repeated lithography processes. The defects may be created during the repeated lithography processes. The recycling defect $\mathrm{CF}$ panels are environmental unfriendly and not cost-effective process. CF repairing is an important cost-effective technical process to improve product yield. In this study, a solvent-less repaired ink system was studied. The optimized formulas of red, green, blue, and black inks have passed the quality control, reliability, and life-time tests. The new solvent-free ink system possesses the balance characteristics in liquid fluidic, UV reactivity, and color saturation. The energy has been conserved without high temperature process for removing organic solvent. The new system exhibits the state-ofthe-art fabrication process without unnecessary energy waste. As a result, the solvent-less CF repair inks offer a promising result for contributing to a low carbon process in the near future.
\end{abstract}

Keywords - Color filter, solvent-less repair inks, liquid crystal display, low carbon process

*pchen@mail.nctu.edu.tw; phone: 886-3-5712121 Ext. 59243; Fax: 886-3-5737681

\section{INTRODUCTION}

Color filter is one of the important components for flat panel displays. The manufacture process involves three repeated lithograph processes for preparing red, green and blue color strips. Defect area may occur during these repeated processes. The flaw products will be removed from production line for repairing process, as shown in Figure 1. High power laser is applied to remove the defect area. The special color photo resist, also called repair ink, is applied to fill up the empty space. Consequently, the product yield will be increased by lowering the defect product rate. Most of color filter repair inks use organic solvents such as propylene glycol monomethyl ether acetate (PGMEA, or PMA) as carrier. The residue solvent needs to be evaporated at high temperature $\left(230^{\circ} \mathrm{C}\right)$ before UV curing process $[1,2]$. In order to conserve the energy, solvent-less system is an important technology breakthrough for the color filter repair process. In this study, we focused on solvent-less repair inks paste development. Monomer, photo active compound (PAC), additives were selected to adjust ink specifications [3]. Specifically, the pigment solid content, ink viscosity, and UV reactivity are key technical issues for the application $[4,5]$.

Emerging Liquid Crystal Technologies VI, edited by Liang-Chy Chien, Hiroshi Yokoyama,

Proc. of SPIE Vol. 7955, 79550E - (C) 2011 SPIE · CCC code: 0277-786X/11/\$18 · doi: 10.1117/12.879130 


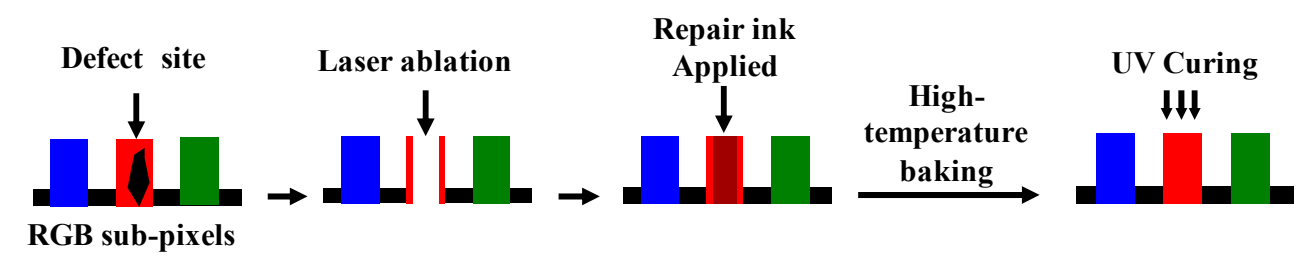

Figure 1 Color filters' defect repair process

\section{EXPERIMENTS}

Red, green, blue, and black ink pastes are co-developed with the manufacturer. Monomer Dipentaerythritol hexaacrylate (DPHA), 1,6-Hexanediol Diacrylate (HDDA) are purchased from Ciba Specialty Chemicals. Photoinitiator, 2-Methyl-1[4-(methylthio)phenyl]-2-morpholinopropan-1-one is purchased from DIC Corporation. Dispersion of repair inks are tuned by the formulation of paste, multi-functional monomer-based polymer, photo initiators, and additives. Repair ink was filled into a cartridge for on-line testing. The color and the reliability analysis are performed for product evaluation.

\section{RESULTS AND DISCUSSION}

In order to avoid the organic solvent system, two fluid monomer system, methyl methacrylate (MMA) and tripropylene glycol diacrylate (TPGDA) were selected for investigation:

\section{(A) MMA monomer system}

The fluid MMA monomer is less volatile than the organic solvent, propylene glycol monomethyl ether acetate (PGMEA). The color pigment was prepared by manufacture. The solid content was adjusted to match solid content of PGMEA ink system. The MMA monomer repair ink system, unfortunately, has much higher viscosity at high pigment content. Therefore, it was not only difficult to be filled in the jetting system, but was also difficult to be applied on the void space. Figure 2 shows the light leakage due to the repair area unable to be fully covered.
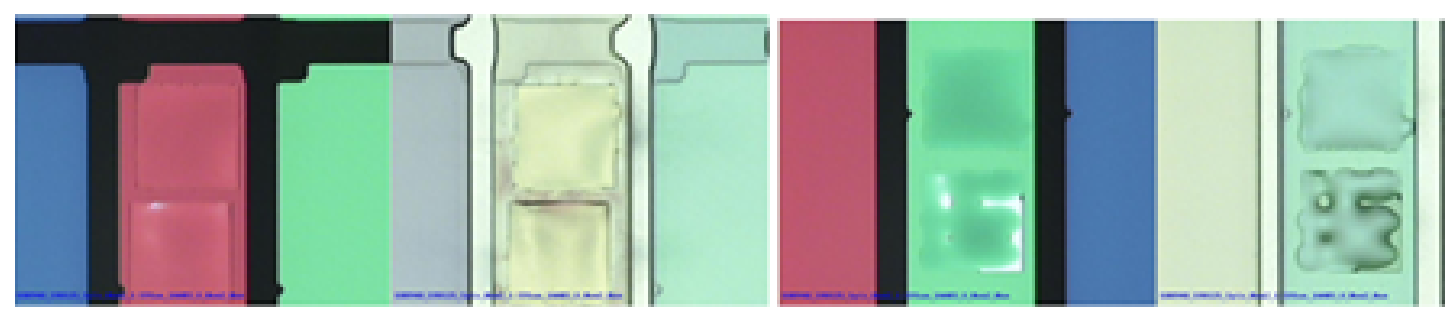

Figure 2. Repair results of the repair ink in the MMA monomer system

\section{(B) TPGDA monomer system}

In order to solve the high viscosity issue, we adopted the tripropylene glycol diacrylate (TPGDA) monomer system. In contrast to the MMA monomer, the TPGDA monomer is less volatile and has lower viscosity. The higher fluidic property has the advantage of filling the stripped area, as shown in Figure 3. The mismatch chromaticity can be found significantly by the naked eye. This drawback is due to low pigments' solid content in the ink mixture. 

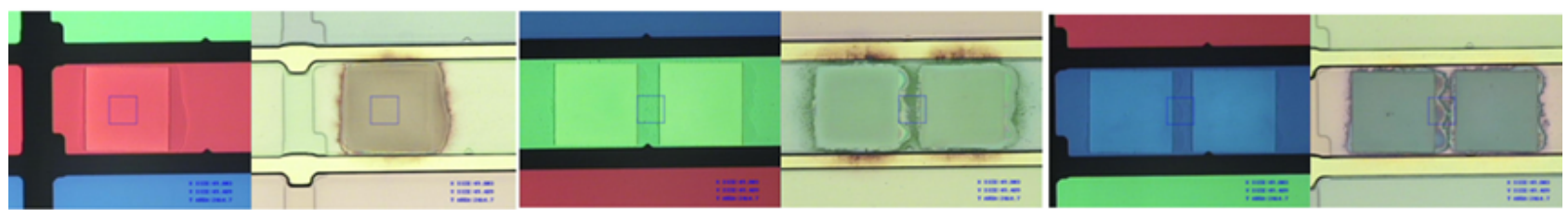

Figure 3. Repair results of the repair ink in the MMA monomer system

\section{(C) MMA / TPGDA monomer system}

With these two color monomer repair ink systems in hand, we tried to balance the fluidic and chromaticity by mixing MMA monomer and TPGDA monomer system. Different ratios of color TPGDA monomer in MMA monomer system were prepared for tests. The viscosity issue in MMA repair ink system and chromaticity issue in TPGDA repair ink system were solved at certain mixing ratio. The rumpled surface, however, was found as shown in Figure 4.

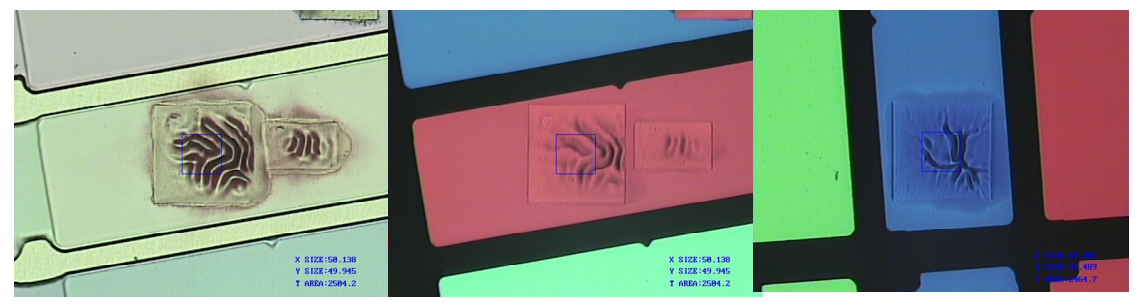

Figure 4. The rumpled surface from the MMA / TPGDA mixed formula.

The SEM analysis suggested that the layer structures were formed during the photo curing process. It may caused by different monomer's reactivity. Higher degree polymerization portion has higher viscosity than lower degree polymerization part. As a result, the wrinkle surface formed due to various viscous flows at different polymerization rate. The attempt was tried to lower repair inks' viscosity to form the flat surface. Low chromaticity and overflow issues, however, re-appeared. The rumple issue was later solved by adjusting monomer ratio and initiator's concentration. Without affecting the repair process, the new monomer system can solve the rumple problem effectively after UV irradiation. The photos of smooth surface of the repaired area are shown in Figure 5.

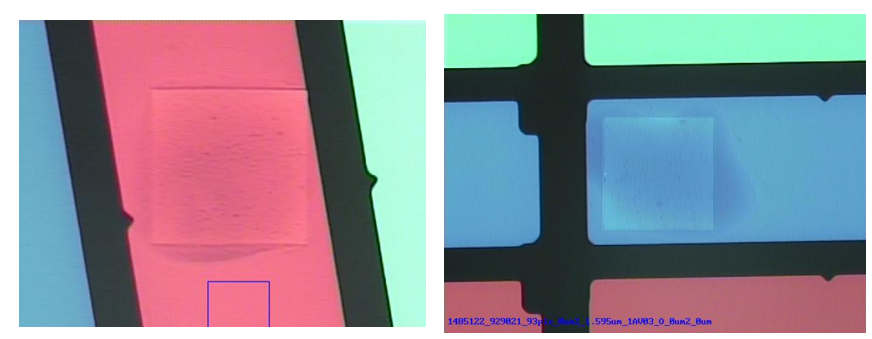

Figure 5. Results of the new MMA / TPGDA mixed formula with smooth surface

The heat, solvent, chemical, and environmental resistance tests were applied to evaluate the final repaired products. The detail specifications are listed in Table 1. The maximum $\triangle$ Euv ${ }^{*}$ needs to be less than 3.0 for the spectral characteristics. The 1931 CIE chromaticity diagram (Commission Intrnationale delEclairage; CIE) of repaired ink pastes indicated that the RGB's NTSC is $65.1 \%$.

Table 1. Reliability tests for RGB repair inks 


\begin{tabular}{|c|c|c|}
\hline Item & Test conditions & $\operatorname{Max}_{\Delta} \mathrm{Euv}^{*}$ \\
\hline \multirow[t]{2}{*}{ Heat test } & $230^{\circ} \mathrm{C}, 1 \mathrm{hr}$ & 2.46 \\
\hline & $200^{\circ} \mathrm{C}, 3 \mathrm{hr}$ & 2.35 \\
\hline \multirow{5}{*}{ Solvent test } & $\begin{array}{l}\text { Ethanol }\left(25^{\circ} \mathrm{C} 、{ }^{60 \mathrm{~min})}\right. \\
230^{\circ} \mathrm{C}, 1 \mathrm{hr}\end{array}$ & 2.92 \\
\hline & $\begin{array}{l}\mathrm{IPA}^{\circ}\left(25^{\circ} \mathrm{C} 、{ }^{60 \mathrm{~min}}\right) \\
230^{\circ} \mathrm{C}, 1 \mathrm{hr}\end{array}$ & 2.93 \\
\hline & TMAH & 1.11 \\
\hline & PK-LCG46 (Cleaning liquid A) & 2.73 \\
\hline & Warm water $\left(80{ }^{\circ} \mathrm{C}, 1 \mathrm{hr}\right)$ & 1.94 \\
\hline Chemical test & 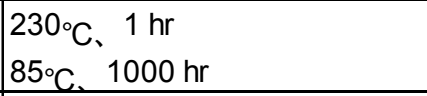 & 1.94 \\
\hline \multirow{5}{*}{ Environment test } & ${ }^{60}{ }^{\circ} \mathrm{C}, \quad 90 \% \mathrm{RH}, 200 \mathrm{hr}$ & 1.94 \\
\hline & $-40{ }^{\circ} \mathrm{C}, 500 \mathrm{hr}$ & 0.61 \\
\hline & $-40 \sim 85^{\circ} \mathrm{C} 30 \mathrm{~min}, 20$ cycle & 0.25 \\
\hline & UV test UV185/254nm & 2.27 \\
\hline & Peeling Test & PASS \\
\hline
\end{tabular}

* $\operatorname{Max}^{\triangle}$ Euv $^{*}$ value is the maximum difference in RGB color inks.

\section{CONCLUSION}

The solvent-less color filter repair inks can be successfully prepared form the mixture of methyl methacrylate (MMA) and tripropylene glycol diacrylate (TPGDA) ink pastes. The cause of rumpled structure was found related to the polymerization process. By adjusting monomer ratio and initiator's concentration, the problem was solved. The optimized formulas of red, green, blue, and black inks have passed the quality control, reliability, and life-time tests. The new solvent-free ink system possesses the balance characteristics in fluidic, UV reactivity, and color saturation. The energy is conserved by getting rid of the high temperature curing process. This new system exhibits the state-of-art fabrication process without unnecessary energy waste. Thus, the solvent-less CF repair inks offer a promising result for contributing to a low carbon process in the near future.

\section{ACKNOWLEDGMENTS}

The authors would like to thank Chung-Hwa Picture Tubes, Ltd. (CPT) for providing Ink repair facilities and financial support in this research.

\section{REFERENCE}

[1] Cheng, T.-S., Lee, H.-Y. and Lee, Ching-Ting Materials Letters, 57, 4578-4582 (2003).

[2] Koo, H.-S., Chen, M. and Pan, P.-C. Thin Solid Films, 515, 896-901 (2006).

[3] Z. W. Wicks, Organic coatings: science and technology : Volume I : Film formation, components, and appearance, John Wiley \& Sons, 1992.

[4] Segurola, J., Allen, N. S., Edge, M., McMahon, A. and Wilson, S. Polymer Degradation and Stability, 64, 39-48 (1999).

[5] Sabnis, R. W. DISPLAYS, 20, 119-124, (1999). 